\title{
JOS Special Section on The Role of Official Statistics in Statistical Capacity Building - Editorial
}

\author{
Irena Ograjenšek ${ }^{1}$
}

The idea of developing a Special Section in the Journal of Official Statistics that would focus on the role of official statistics in statistical capacity building was formed at the 2013 World Statistics Congress in Hong Kong. It emerged within the framework of a Special Topic Session entitled Official Statistics in the Service of Business and Industrial Statisticians that I organized and chaired.

The papers presented in that session focused entirely on the relationship between official statistics on one hand, and business and industrial statistics on the other hand. However, the subsequent lively discussion (thanks to Special Topic Session discussant Carol Joyce Blumberg) went beyond the service relationship described in the session title. The issue of statistical capacity building - for many decades one of the primary goals of the International Statistical Institute and affiliated associations - and the role of official statistics in it came to the fore along with many other important related topics. Now, after the World Statistics Congress, to my great satisfaction, some of these topics are systematically addressed in the papers included in this Special Section.

The section is divided by theme into four related parts.

The first part deals with the role of official statistics in the 21st century. In this framework, Steve MacFeely addresses the need for continuous evolution of official statistics by emphasizing the fact that change always simultaneously presents threats and offers opportunities.

The second part is dedicated to official statistics and statistical capacity building in practice. Here, Sharleen Forbes and Alan Keegan present experiences from New Zealand with targeted efforts to raise the official statistics capability among government employees, while Tomi Deutsch uses the case of the Consumer Price Index to discuss statistical capacity building among official statisticians.

The third part contains what I like to refer to as the future outlook. In this framework, Shirley Coleman presents data mining opportunities in official statistics that small and medium-sized enterprises can use to enhance their business opportunities. Her paper is followed by Ron Kenett's and Galit Shmueli's description of a journey from 'generic' data quality to what they refer to as Information Quality (InfoQ) in official statistics. Last, but not least, Luciana Dalla Valle presents a flexible methodology which uses official statistics to deal with self-selection bias in survey data collection processes.

${ }^{1}$ University of Ljubljana, Faculty of Economics, Kardeljeva pl. 17, 1000 Ljubljana, Slovenia. Email: irena.ograjensek@ef.uni-lj.si 
The fourth and final part contains two invited commentaries. In the first one, John Pullinger, the United Kingdom's National Statistician, presents his take on the role of official statistics in statistical capacity building. He systematically discusses all relevant aspects, starting with the historical perspective, continuing with the interplay of national and global capacity building efforts, and concluding with the data revolution challenge. In the second commentary, Marleen De Smedt, Advisor to the Director-General of Eurostat, explains how Eurostat currently addresses the needs of official statistics users.

This Special Section could not have been prepared without the support of very significant people. I am much indebted to the colleagues who accepted my invitation to review submissions and profoundly thank them for their careful work and insightful contributions. Special thanks go to JOS Editors-in-Chief Ingegerd Jansson and Annica De Groote, as well as Susanna Emanuelsson from the JOS Editorial Office, for their continuous support during the entire editorial process.

I hope you will find the Special Section informative and inspirational.

Irena Ograjenšek Guest Editor 